\title{
Case Report \\ Successful treatment of meticillin-resistant Staphylococcus aureus bacteraemia in a neonate using daptomycin
}

\author{
Correspondence \\ Abid Hussain \\ abid.hussain@heartofengland.nhs. \\ uk
}

Received 15 October 2010

Accepted 2 December 2010

\author{
Abid Hussain, ${ }^{1}$ Venkatesh Kairamkonda ${ }^{2}$ and David Richard Jenkins ${ }^{1}$ \\ ${ }^{1}$ Department of Clinical Microbiology, University Hospitals of Leicester NHS Trust, \\ Leicester LE1 5WW, UK \\ ${ }^{2}$ Department of Child Health, University Hospitals of Leicester NHS Trust, Leicester LE1 5WW, UK
}

\begin{abstract}
Daptomycin is licensed for the management of Staphylococcus aureus infections in adults, including those caused by meticillin-resistant $S$. aureus (MRSA). Few data exist on paediatric use or dose guidance in neonates. We report the case of a neonate with MRSA bacteraemia successfully managed with daptomycin. Dose requirements were substantially higher than those recommended for adults.
\end{abstract}

\section{Case report}

A male, the first of diamniotic dichorionic twins, $27+4$ weeks' gestation, $980 \mathrm{~g}$ birth weight, was born by emergency Caesarean section for threatened preterm labour at an out-of-area neonatal unit. He was electively intubated at birth and given surfactant and empirical intravenous (i.v.) benzylpenicillin and gentamicin. These antimicrobials were stopped after $48 \mathrm{~h}$ subsequent to normal inflammatory markers and sterile peripheral blood cultures. Total parenteral nutrition was commenced from day 1 via an internal jugular central venous catheter. A routine echocardiogram demonstrated a moderate-sized patent ductus arteriosus.

On subsequent transfer to our tertiary neonatal unit on day 22, the patient was screened for meticillin-resistant Staphylococcus aureus (MRSA) (nose, umbilicus and perineum) according to routine protocol for interhospital transfers.

On day 23 , the patient developed a temperature of $37.5{ }^{\circ} \mathrm{C}$, mild hyperglycaemia and brief episodes of oxygen desaturation and bradycardia. A pustule was noted on the dorsum of his right hand, at the insertion site of a prior i.v. cannula. After blood culture collection, flucloxacillin and gentamicin were commenced. Subsequently, MRSA was grown from the blood culture and the admission MRSA screening swabs. Antibiotics were changed to vancomycin for MRSA therapy and cefotaxime for empirical Gram-negative cover. Quantitative susceptibility testing was performed by inoculating Iso-Sensitest agar (Oxoid) with a $0.5 \mathrm{McF}$ arland suspension and applying an antibiotic-impregnated Etest strip (AB Biodisk). The results of this were as follows: vancomcyin $1.5 \mathrm{mg} \mathrm{l^{-1 }}$, teicoplanin $1.5 \mathrm{mg} \mathrm{l}^{-1}$, daptomycin $0.19 \mathrm{mg} \mathrm{l}^{-1}$, linezolid

Abbreviation: i.v., intravenous.
$1.5 \mathrm{mg} \mathrm{l}^{-1}$ and tigecycline $0.094 \mathrm{mg} \mathrm{l}^{-1}$. The vancomycin MIC prompted a switch to daptomycin after $24 \mathrm{~h}$ of vancomycin therapy. Given the concern that neonates may have increased renal clearance of daptomycin, the starting dose was $10 \mathrm{mg}$ ( $\mathrm{kg}$ body weight $)^{-1}$ once daily i.v. The dose was administered by slow i.v. infusion over $40 \mathrm{~min}$. Therapeutic drug levels were performed by a validated HPLC assay to guide dose adjustments (Tobin et al., 2008). Serum levels, taken peripherally, were monitored by trough levels and $1 \mathrm{~h}$ post-infusion levels. Consequently, the dose was increased on day 33 of life to $15 \mathrm{mg} \mathrm{kg}^{-1}$ once daily i.v. (Fig. 1). The patient successfully and uneventfully completed 14 days of daptomycin treatment with clinical cure. Creatine kinase levels were monitored in addition to routine biochemical and haematological parameters but these remained in the normal range $\left(<350 \mathrm{IU} \mathrm{l}^{-1}\right)$. Serum creatinine levels were consistently less than $20 \mu \mathrm{mol} \mathrm{l}^{-1}$ (normal range $34-76 \mu \mathrm{mol}^{-1}$ ). Six months later, there has been no relapse.

The MRSA isolates were sent to the Staphylococcal Reference Laboratory, Health Protection Agency, London, UK, which confirmed a widespread sporadic phage type. From the PFGE pattern, an inferred multilocus sequence type of clonal complex 45 was reported (Dr Angela Kearns, personal communication).

\section{Discussion}

Daptomycin, a cyclic lipopeptide antibiotic, is currently licensed for the management of complicated skin and soft tissue infections, S. aureus bacteraemias and right-sided endocarditis in adults.

Several in vitro studies have demonstrated that the effects of daptomycin on the cell membrane are concentrationdependent, rapid and unlike those of any other antibiotic 


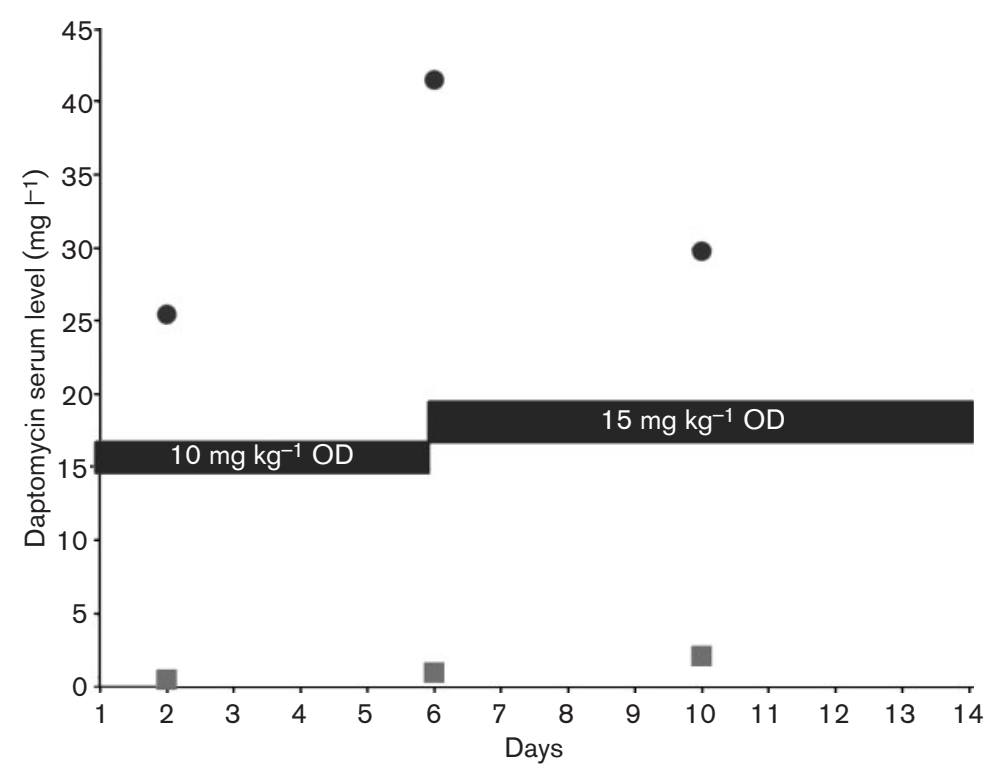

Fig. 1. Daptomycin serum levels $\left(\mathrm{mg} \mathrm{I}^{-1}\right)$. Filled squares, pre-dose levels; filled circles, post-dose levels; OD, once daily. Days refers to the duration of daptomycin treatment.

class (Kanafani \& Corey, 2007). In the presence of calcium, daptomycin inserts into the bacterial membrane, forming an ion channel that allows the release of potassium ions and subsequent cell membrane depolarization and cell death (Hawkey, 2008).

Vancomycin is the usual treatment for MRSA bacteraemia in the UK but there is increasing concern that isolates with vancomycin MICs that are raised may not be adequately treated with standard vancomycin doses (Carey \& Long, 2010), with clinical failure rates of $50 \%$ as the vancomycin MIC approaches $2 \mathrm{mg} \mathrm{l}^{-1}$ (Yoon et al., 2010). Treatment of MRSA bacteraemia is successful in only $9.5 \%$ of cases when the MIC is $\geqslant 2 \mathrm{mg} \mathrm{l}^{-1}$, specifically if the ratio of the area under the $24 \mathrm{~h}$ serum vancomycin concentration curve $\left(\mathrm{AUC}_{24}\right)$ to the vancomycin MIC of the infecting organism $\left(\mathrm{AUC}_{24} / \mathrm{MIC}\right)$ is less than 400 (Moise et al., 2007). Studies have demonstrated that patients with isolates having vancomycin MICs of $\geqslant 1.5 \mathrm{mg} \mathrm{l}^{-1}$ had a 2.4-fold increase in failure compared to patients with isolates showing MICs of $<1.0 \mathrm{mg} \mathrm{l}^{-1}(P<0.05)$ (Lodise et al., 2008). Daptomycin may be considered as preferred treatment for the therapy of MRSA bloodstream infections in adults, particularly when vancomycin MICs are $>1 \mathrm{mg}$ $1^{-1}$. There are currently no data on outcomes of patients $<18$ years with MRSA bacteraemias. Published data from adults have shown that daptomycin pharmacokinetic curves are linear through the dose range $0.5-6 \mathrm{mg} \mathrm{kg}^{-1}$, with a slight $(20 \%)$ non-linearity in the area under the curve and trough concentration at a higher dose $(8 \mathrm{mg}$ $\mathrm{kg}^{-1}$ ), with a half-life of $9 \mathrm{~h}$, a volume of distribution of $0.1 \mathrm{l} \mathrm{kg}^{-1}$ and systemic clearance of $8.2 \mathrm{ml} \mathrm{h}^{-1} \mathrm{~kg}^{-1}$ (Dvorchik et al., 2003). Adult volunteers treated with $6 \mathrm{mg}$ $\mathrm{kg}^{-1}$ per dose every $24 \mathrm{~h}$ attained mean peak and trough serum concentrations of $86 \pm 7.1 \mathrm{mg} \mathrm{l}^{-1}$ and $9 \pm 1.1 \mathrm{mg}$ $1^{-1}$. Two full-term neonates treated with daptomycin achieved peak levels of $41.7 \mathrm{mg}^{-1}$ and $36.7 \mathrm{mg} \mathrm{l}^{-1}$, respectively, when treated with $6 \mathrm{mg} \mathrm{kg}{ }^{-1}$ (CohenWolkowiez et al., 2008), suggesting that rates of clearance may be higher in children, and that there is an ageassociated change in plasma clearance (Abdel-Rahman et al., 2008).

MRSA bacteraemia in the neonatal period is well characterized. In a recent survey, $61 \%$ of paediatric MRSA bacteraemia cases were in children aged under 1 year and $35 \%$ were in the neonatal period (Johnson et al., 2010).

The notable discrepancy in the serum levels between $10 \mathrm{mg}$ $\mathrm{kg}^{-1}$ and $15 \mathrm{mg} \mathrm{kg}^{-1}$ daptomycin dosing may be due to the child's systemic inflammatory response syndrome resulting in physiological collection of fluid in the third space. A post-antibiotic effect of daptomycin against $S$. aureus would explain success of therapy even though the trough levels approached the MIC of the organism. Once daily dosing, as opposed to divided doses, appears to reduce the toxicity, and would be appropriate for neonates.

\section{Conclusions}

Daptomycin may be considered as a first-line treatment in children with MRSA bacteraemia when the vancomycin MIC is $\geqslant 1.5 \mathrm{mg} \mathrm{l}^{-1}$. This indication is unlicensed; however, we have demonstrated tolerability of daptomycin at higher than accepted doses in our case. There are only limited data on the pharmacokinetics, safety and efficacy of daptomycin in children, and further work is required in this area (Abdel-Rahman et al., 2008). Future pharmacokinetic studies in this population should reflect the larger neonatal volume of distribution and faster renal clearance when considering dose selection of daptomycin. Daptomycin serum levels should be monitored to assess effective and safe dosing, at least until there is greater 
experience of use in the paediatric age group. Creatine kinase levels should be monitored during therapy. Studies of daptomycin in the paediatric population are needed to assess its safety, effectiveness, pharmacodynamics and pharmacokinetics. The apparent requirement to use much higher doses in neonates should be noted and investigated further.

\section{References}

Abdel-Rahman, S. M., Benziger, D. P., Jacobs, R. F., Jafri, H. S., Hong, E. F. \& Kearns, G. L. (2008). Single-dose pharmacokinetics of daptomycin in children with suspected or proved gram-positive infections. Pediatr Infect Dis J 27, 330-334.

Carey, A. J. \& Long, S. S. (2010). Staphylococcus aureus: a continuously evolving and formidable pathogen in the neonatal intensive care unit. Clin Perinatol 37, 535-546.

Cohen-Wolkowiez, M., Smith, P. B., Benjamin, D. K., Jr, Fowler, V. G., Jr \& Wade, K. C. (2008). Daptomycin use in infants: report of two cases with peak and trough drug concentrations. J Perinatol 28, 233-234.

Dvorchik, B. H., Brazier, D., DeBruin, M. F. \& Arbeit, R. D. (2003). Daptomycin pharmacokinetics and safety following administration of escalating doses once daily to healthy subjects. Antimicrob Agents Chemother 47, 1318-1323.
Hawkey, P. M. (2008). Pre-clinical experience with daptomycin. J Antimicrob Chemother 62 (Suppl. 3), iii7-iiil4.

Johnson, A. P., Sharland, M., Goodall, C. M., Blackburn, R., Kearns, A. M., Gilbert, R., Lamagni, T. L., Charlett, A., Ganner, M. \& other authors (2010). Enhanced surveillance of methicillin-resistant Staphylococcus aureus (MRSA) bacteraemia in children in the UK and Ireland. Arch Dis Child 95, 781-785.

Kanafani, Z. A. \& Corey, G. R. (2007). Daptomycin: a rapidly bactericidal lipopeptide for the treatment of Gram-positive infections. Expert Rev Anti Infect Ther 5, 177-184.

Lodise, T. P., Graves, J., Evans, A., Graffunder, E., Helmecke, M., Lomaestro, B. M. \& Stellrecht, K. (2008). Relationship between vancomycin MIC and failure among patients with methicillinresistant Staphylococcus aureus bacteremia treated with vancomycin. Antimicrob Agents Chemother 52, 3315-3320.

Moise, P. A., Sakoulas, G., Forrest, A. \& Schentag, J. J. (2007). Vancomycin in vitro bactericidal activity and its relationship to efficacy in clearance of methicillin-resistant Staphylococcus aureus bacteraemia. Antimicrob Agents Chemother 51, 2582-2586.

Tobin, C. M., Darville, J. M., Lovering, A. M. \& Macgowan, A. P. (2008). An HPLC assay for daptomycin in serum. J Antimicrob Chemother 62, 1462-1463.

Yoon, Y. K., Kim, J. Y., Park, D. W., Sohn, J. W. \& Kim, M. J. (2010). Predictors of persistent methicillin-resistant Staphylococcus aureus bacteraemia in patients treated with vancomycin. J Antimicrob Chemother 65, 1015-1018. 